\title{
NETmundial: only a landmark event if 'Digital Cold War' rhetoric abandoned
}

\author{
Francesca Musiani \\ MINES ParisTech, France, francesca.musiani@mines-paristech.fr
}

\section{Julia Pohle}

Studies on Media, Information and Telecommunication research centre, Vrije Universiteit Brussel, Belgium,jpohle@vub.ac.be

Published on 27 Mar 2014 | DOI: 10.14763/2014.1.251

\begin{abstract}
While internet privacy has been a central concern for quite a long time, the revelations by Edward Snowden about the US National Security Agency's massive surveillance programme have highlighted the extent to which it is a core political issue. The privacy-surveillance controversy has prompted what is perhaps the most prominent and ambitious call in internet governance history to break the dominance of the United States' control over internet infrastructure: the Global Multistakeholder Meeting on the Future of Internet Governance, or NETmundial (April 2014). The article analyses the current state of multi-stakeholderism in internet governance in light of this event. In particular, it argues for the necessity to leave the 'Digital Cold War' rhetoric behind if the internationalisation and the globalisation of internet governance is to move to the next level.
\end{abstract}

Keywords: Internet governance, Multi-stakeholderism, Net Mundial, Digital Cold War, United States of America

\section{Article information}

Received: 19 Mar 2014 Reviewed: 25 Mar 2014 Published: 27 Mar 2014

Licence: Creative Commons Attribution 3.0 Germany

Competing interests: The author has declared that no competing interests exist that have influenced the text.

URL:

http://policyreview.info/articles/analysis/netmundial-only-landmark-event-if-digital-cold-war-rhetoricabandoned

Citation: Musiani, F. \& Pohle, J. (2014). NETmundial: only a landmark event if 'Digital Cold War' rhetoric abandoned. Internet Policy Review, 3(1). https://doi.org/10.14763/2014.1.251

Over the last year, the continuous revelations by Edward Snowden about the massive surveillance data mining programmes of the US National Security Agency (NSA) have led to what can be considered a "wake-up call" for global internet governance. They have entailed, among several of their important consequences, an exacerbation of the differences between the more or less established actors in today's internet governance landscape. While privacy and its transposition to the internet context has been a central concern for quite a long time, the 
Snowden revelations have highlighted the extent to which it is a core political issue, with intense national interests, as well as individual ones, taking shape around it. Around this tension, challenges to offshore internet governance from the United States and to assume local or regional control of data fluxes have multiplied, coming most notably from Brazilian President Dilma Rousseff and German Chancellor Angela Merkel.

The privacy-surveillance controversy has prompted what is perhaps the most prominent and ambitious call in internet governance history to break the dominance of United States control on internet infrastructure and to move the internationalisation and the globalisation of internet governance $_{1}$ to the next level: the Global Multistakeholder Meeting on the Future of Internet Governance, or NETmundial. Scheduled for April 23 and 242014 in Sao Paulo, Brazil, the meeting is set to focus on "crafting Internet governance principles and proposing a roadmap for the further evolution of the Internet governance ecosystem" 2 - with a very thinly veiled objective to undermine US predominance, and a newly found legitimacy prompted by the Snowden revelations. Recently, the expectations of the global internet governance community about this meeting were additionally fueled by the United States government's declarations that it is time to take a "step back" in its control over the Internet Corporation for Assigned Names and Numbers (ICANN) (DoC, 2014).

\section{'DIGITAL COLD WAR': MISLEADING LABELS REVISIT OLD CONFLICTS}

While, as internet governance scholar Milton Mueller has noticed, “the US government's attempt to position itself as the standard-bearer of Internet freedom, always dubious, was finished off" through the disclosure of the NSA surveillance programmes (Mueller, 2013a), the PRISM scandal was maybe the last, but surely not the only recent event that challenged the status quo of the internet governance landscape. Two years ago, in the aftermath of the World Conference on International Telecommunications (WCIT), we could witness a confrontation between internet stakeholders, misleadingly labelled by several commentators as the beginning of a 'Digital Cold War' in internet governance.

During this conference, which was held by the International Telecommunication Union (ITU) in December 2012 and aimed at renegotiating its outdated international telecommunication regulations, several countries - among them the United States, Britain, Sweden and Japan eventually refused to sign the final agreement. Their dissent was motivated by the inclusion of a non-binding resolution that could be construed as inviting the ITU to take over a more important role in global internet governance. The US and like-minded governments saw in it an endeavour by more authoritarian governments - above all from Russia, China and some Arab countries - to overrule the existing multistakeholder structures of internet governance in order to regain more governmental control both on an international level and with regard to 'national internet segments'.

Yet, the Digital Cold War rhetoric, which was taken over by media and high-level policymakers (e.g., The Economist, 2012; Kroes, 2013) was misleading as it simplified the controversy over differing models of global internet governance by framing it as an ideological conflict between two blocks: one ostensibly in favour of a free, open, human rights-based and multistakeholdergoverned internet, and the other advocating the extension of national sovereignty on cyberspace, which would reputedly lead to more control, surveillance and censorship of national 
and cross-border internet traffic. In addition, this analogy was highly problematic as it entirely failed to recognise legitimate concerns of countries, many of them from the developing world, that are on the losing side of the actual internet model and seek for increased intergovernmental influence for other reasons than those mentioned before. At the same time, the comparison with the ideological confrontations of the Cold War attempted to hide the actual geopolitical, economic, military and cultural interests of those stakeholders defending the status quo.

But the WCIT episode is only one recent example in a long series of confrontations between supposedly irreconcilable visions about who should govern the internet. Debates about the ideal governance model for the 'network of networks' first arouse in the period leading up to ICANN's foundation in 1998, which overruled alternative proposals put forward by the Internet Society (ISOC) or the ITU, and reached their first peak during the World Summit on the Information Society (WSIS) in 2003-2005 (Kleinwächter, 2004). Ever since, international debates on internet governance are dominated by subliminal or explicit tensions between adherers of different governance visions. But are these visions indeed hopelessly heterogeneous? Will events like NETmundial - with its implicit but clear "counter-hegemony" stance, only exacerbate differences? Will NETmundial specifically allow for bridges to be built? Will it open new directions for the overcoming of confrontational perspectives, as well as for the benefit of a more constructive and inclusive approach to internet governance?

\section{MULTISTAKEHOLDERISM, A COMPROMISE WITH CAVEATS}

For a better understanding of the challenge that NETmundial is facing, it is necessary to have a closer look at these competing governance visions: in less ideologically loaded terms, they consist, on the one hand, in a model that preserves the classical intergovernmental approach to global governance, in which governments - for instance cooperating through the United Nations and the ITU - have the exclusive right for making public policy; this model is envisioned by most non-democratic countries, but also a number of developing countries and emerging democracies which until now have no or very little impact in the existing governance structures and see the intergovernmental model as the most efficient way to gain greater influence on global decision-making with regard to the internet.

On the other hand, the currently only discussed alternative consists in the so-called multistakeholder model, in which new global institutions - in particular ICANN and the Internet Governance Forum (IGF) - challenge the exclusivity of governmental policy-making by favouring an increased participation of various non-state parties. This concept of multistakeholderism reflects the idea that every "holder of interests" in the internet should be able to have a voice heard in the shaping of the network of networks; processes and arenas should be provided for them to do so in a coordinated way (Levinson, 2010). Hailed in the early 2000 s as the "21st-century way" of engaging in world politics, the multistakeholder model is recently being put under the magnifying glass by practitioners and researchers alike, in search of model-specific results and metrics to assess them (Drake, 2011). In the meantime, and even though it is often criticised from various sides, the multistakeholder model continues to be implemented not only in the IGF, but also in newly-created venues such as NETmundial or the Global Commission on Internet Governance created in early 2014 by the Centre for International Governance Innovation and the Chatham House. But instead of developing innovative forms of multistakeholder participation, these venues have been criticised for 
displaying "an incredible degree of isomorphism with existing organizational structures in Internet governance" as they appear to bear strong similarities with the setup of the IGF or ICANN (Kuerbis, 2014).

Astonishingly enough, a large number of governments seem deliberately to ignore the fact that the multistakeholder scenario, as described above, already represents a compromise, as it departs from two more radical scenarios, which also have strong proponents. These consist, firstly, in unrestricted self-regulation of the internet by an entirely independent technical and academic community (as imagined by the 'cyberlibertarian' internet pioneers) and, secondly, in the total privatisation of all internet management functions and the (quasi-) absence of any governmental or regulatory oversight (the neo-liberal vision as officially favoured by the US government at ICANN's foundation). Both of these governance models existed since the internet's beginning and shaped significantly more its technical and operational management than the intergovernmental approach that historically prevailed in other fields of telecommunications. As a consequence, advocates of the multistakeholder model present their solution as the ideal middle ground between opposed visions of internet governance. However, they fail to concede that the currently existing internet governance ecosystem does not - or only partly - correspond to this ideal: While it might allow various stakeholders to participate in internet governance processes, the current multistakeholder processes do not necessarily lead to a wider range of views or a more global representation of interests and concerns (Drake, 2011). In several instances, it actually tends to increase the overrepresentation of actors from Western highly-developed countries in all stakeholder groups, whereas it disprivileges - for instance developing countries, which often lack independent civil society networks or strong business players that could meaningfully engage in the existing internet governance structures (Cogburn, 2006; Calandro et al., 2013).

In the long run, the main discrepancy in current debates about global internet governance, hence, is not only caused by stakeholders, who call for a different, more conservative intergovernmental approach, but also by those who lack to acknowledge that the current situation is still far from reflecting the ideal model they propagate.

\section{WHAT STANDS IN THE WAY OF A RELOADED MULTISTAKEHOLDERISM}

There are three main problems that prevent the existing internet governance system from attaining a more ideal version of 'multistakeholderism'. The first two originated during the WSIS: The final statement of the summit (Tunis Agenda, 2005) included an "ugly and unworkable compromise" on internet governance "that seemed to endorse multistakeholder governance, but actually undermined it by assigning different 'roles' to each major stakeholder group" (Mueller, 2013b); it attributed exclusive public policy authority to states and intergovernmental organisations, while assigning the responsibility for technical and operational questions to the private sector. It thereby created an artificial and unrealisable separation of intertwined political and technical matters, and placed governments on the top of the internet decision-making pyramid - a position that, in reality, they held neither back then, nor today. Likewise, it fully misrepresented the contribution of civil society and the technical community to the existing governance structures as it simply requested them to play an 'important role' on the 'community level'. 
In addition, the WSIS outcome created a second major problem as it failed to take a clear stance on the institutional framework, in which future decisions about global internet governance should be taken. Instead, it postponed a forceful decision by creating the IGF as a forum for multistakeholder dialogue, but without equipping it with the necessary decision-making capacities. As a consequence, today - nine years and eight IGF editions later - we witness a growing multitude of internet governance events, with NETmundial being the most prominent example. We also see an increasing variety of intergovernmental or multistakeholder committees and resources dealing with various internet-related aspects, which render the creation of a unique, global and all-embracing internet governance setting even more difficult.

The third main problem of the current internet governance ecosystem predates the WSIS, as it is related to the privileged role of the United States government within the existing structures. During ICANN's creation, the US government imposed direct oversight over the corporation's technical decision-making procedure with a Memorandum of Understanding between the newly founded organisation and the US Department of Commerce (DoC). In contrast, other governments were only granted a consultative status through ICANN's Governmental Advisory Committee (GAC). Even if over the last 15 years the GAC's influence has increased and the original agreement between ICANN and the DoC was altered several times, the DoC still regulates the technical functions that the Internet Assigned Numbers Authority (IANA) executes as a separate entity within ICANN. As a consequence, the management of the internet's core infrastructure still remains under US oversight, which explains other stakeholders' concerns that the United States could prominently steer policy decisions linked to the technical development of the online space. In light of this unilateral influence on ICANN as one of the core institutions of the current internet governance landscape, the US rejection of other national governments' claims for more influence, as witnessed during the WCIT meeting in 2013, appears almost hypocritical. But this may be bound to change as of March 2014...

\section{THE 'STEP BACK' OF THE UNITED STATES}

While the organisers of NETmundial promise to set a new landmark in multistakeholder proceedings (implicitly criticising not only US predominance, but also the actual effectiveness of multistakeholder "pioneers" like the IGF), the United States government may be seeking to anticipate some of the arguments against its historical privileged relationship to ICANN, by demonstrating its willingness to be the first in taking a step back.

On March 14 2014, the US DoC announced that it would surrender its most direct means of control over internet infrastructure. Assistant Secretary of Commerce Lawrence Strickling declared that he asked ICANN to start a formal transition process so as to "support and enhance the multistakeholder model" and "maintain the openness of the Internet" (DoC, 2014). ICANN Chief Executive Fadi Chehadé added, on his end, that he aimed for the process to be completed before ICANN's management contract with the DoC expires in September 2015 (Timberg, 2014). Even if accompanied by another statement, insisting that the task should not be undertaken by another group of governments or an exclusively intergovernmental organisation (the historical opposition to ITU and its offspring, like WCIT, is obvious), the United States have never been more direct in suggesting a new step towards the globalisation of internet governance. By suggesting that the new phase should be undertaken by an arrangement that includes "the private sector and other interested parties," it may indeed be declaring its endorsement for the multi-national, not over-institutionalised version of multistakeholderism fostered by NETmundial. 
The most recent ICANN meeting, held in Singapore between March 21 and 27, shows that reactions to the US announcements are mixed - in particular because the modalities of the transition process, the names of the people who will be in charge, and the shape that a new accountability mechanism should take, are still all but defined. Therefore, it can be hoped that NETmundial will be an important occasion to further clarify stakeholders' respective roles in the roadmap for transition. European Commission Vice-President, and Commissioner for the Digital Agenda, Neelie Kroes, has commented the decision in a positive light, calling it a "historical announcement" on her Twitter profile. However, other actors coming from both the political realm and the private sector consider this a strategic problem. Increasing internationalisation - in form of more intergovernmental oversight over the IANA functions may also mean additional power and control in the hands of authoritative states like China and Russia. This may add a new dimension to a scenario where distributed denial of service attacks and attempts to seize industrial secrets via the internet (to name but two examples) are increasingly frequent proxies for the more classical weapons of war yielded in the past. If the conflict extends to the most critical pieces of internet infrastructure (such as the Domain Name System), can the stability and the security of the global "network of networks" afford it? Experts seem to be unanimous: it is not the case (e.g. DeNardis, 2014).

\section{THE UN'S INDECISIVENESS COMES AT A COST}

With all of this in mind, one could expect that the United Nations would try to play a more crucial role on internet governance issues, and use its 10 years review of the WSIS in 2015 to find a long-term global solution to an internet governance that all stakeholders can agree with. But so far, discussions on the modalities of the review process are undermined by countries, which either fear that the reassessment could lead to new intergovernmental agreements about alternative internet governance scenarios, or suspect that it would only be used to confirm the status quo of the current multistakeholder structure. Hence, by continuously postponing all decisions about the format and content of the WSIS review, the United Nations are once more missing out on the occasion to significantly influence global internet governance.

In the meantime, deliberations continue to take place outside of the United Nations. NETmundial, in particular, due to ICANN's important role and the confirmed support of the event by the US government (Sepulveda, 2014), might take up many of the points that the WSIS had left unfinished and develop first recommendations about the transition plan for ICANN's oversight. However, due to the fact that NETmundial is entirely based on a multistakeholder vision of internet governance, it can already be suspected that advocates of the classical intergovernmental governance model will not accept the outcomes of the meeting as a new common ground for global internet governance and continue to seek alternative solutions within the domain of the United Nations.

When considering the last ten years of increasing multistakeholderism in internet governance, it becomes apparent that the 'Future of Internet Governance' can only lie at the crossroads of opposite visions of governance: taking into account the evolving and re-dimensioned role of nation-states, the ever-more important role of the private sector, and the complexities hidden behind a too generic 'civil society' label. A turn to an exclusive, intergovernmental approach, as wished for by some UN member states with support of the ITU, would not do justice to the history of the internet governance ecosystem and its multitude of stakeholders. At the same time, those countries and actors who benefit from the current system, cannot afford hiding behind rhetorical iron curtains and continue to exclude the rest of the world - especially 
developing countries and emerging economies, which for structural reasons might often not be represented by others than their governments - from the governance of the most important global technological network of our times.

NETmundial and the recent announcement of the United States to cede their unilateral control over the internet infrastructure are just small steps towards the much bigger change that is urgently needed. Because today's imperfect, non-transparent and unbalanced multistakeholder model, just as any other scenarios which fail to consider the rights and interests that all countries and all stakeholders have in the governance of cyberspace, only increases the risk that, in the future, there will be no global internet but many national and regional internets, each governed in a different way.

\section{FOOTNOTES}

1. Within the internet governance community, the term 'internationalisation' is commonly used to describe a stronger role of governments in the internet governance processes, while 'globalisation' refers to an increase of global non-governmental participation.

2. For the objectives and concrete setup of the Global Multistakeholder Meeting on the Future of Internet Governance, see: http://netmundial.br/ 


\section{REFERENCES}

Calandro, E., A. Gillwald \& N. Zingales (2013). Mapping Multistakeholderism in Internet Governance: Implications for Africa. Report, Research ICT Africa. Retrieved from http://www.researchictafrica.net/docs/Mapping_Multistakeholderism_in_Internet_Governan ce.pdf

Cogburn, D. (2006). “Inclusive Internet Governance: Enhancing Multistakeholder Participation Through Geographically Distributed Policy Collaboratories," in J. Kurbalija and V. Katrandjiev, Global Multistakeholder Diplomacy. Malta/Geneva: DiploFoundation.

DeNardis, L. (2014). The Global War for Internet Governance. New Haven, CT: Yale University Press.

Drake, W. (2011). "Multistakeholderism: External Limitations and Internal Limits.” MIND:

Multistakeholder Internet Dialog, Co:llaboratory Discussion Paper Series No. 2, Internet Policymaking, 68-72, Berlin: Co:llaboratory.

The Economist (2012). “A Digital Cold War?”, The Economist, 14/12/2012. Retrieved from http://www.economist.com/blogs/babbage/2012/12/internet-regulation

Kleinwächter, W. (2004). "Beyond ICANN Vs ITU? How WSIS Tries to Enter the New Territory of Internet Governance”. Gazette 66 (3-4): 233-51.

Kroes, N. (2013). “Stopping the Digital Cold War”, Speech delivered by Neelie Kroes, VicePresident of the European Commission responsible for the Digital Agenda, 28/02/2013. Retrieved from http://europa.eu/rapid/press-release_SPEECH-13-167_en.htm

Kuerbis, B. (2014). “The 'Iron Cage' of Multistakeholder Governance”, Blog of the Internet Governance Project (IGP), 28/01/2014. Retrieved from

http://www.internetgovernance.org/2014/01/28/the-iron-cage-of-multistakeholder-governanc $\mathrm{e} /$.

Levinson, N. (2010). "Co-creating Processes in Global Governance: the Case of the Internet Governance Forum”. Proceedings of the Fifth Annual Global Internet Governance Academic Network Conference, Vilnius, Lithuania.

Mueller, M. (2013a). “Are we in a Digital Cold War?”, GigaNet workshop 'The Global Governance of the Internet: Intergovernmentalism, Multistakeholderism and Networks'. Geneva, 17/05/2013.

Mueller, M. (2013b). "Revisiting 'roles:' On the agenda for Brazil”, Blog of the Internet Governance Project (IGP), 18/12/2013. Retrieved from http://www.internetgovernance.org/2013/12/18/revisiting-roles-on-the-agenda-for-brazil/.

Sepulveda, D. A. (2014). 'Geopolitics and Future of the Internet', Speech delivered by US Ambassador Daniel A. Sepulveda, 23/01/2014. Retrieved from http://translations.state.gov/st/english/texttrans/2014/o1/20140125291640.html\#ixzz2skwBO ygd 
Timberg, C. (2014). U. S. to relinquish remaining control over the Internet. Washington Post, 14/03/2014. Retrieved from http://www.washingtonpost.com/business/technology/us-to-relinquish-remaining-control-ove r-the-internet/2014/03/14/oc7472do-abb5-11e3-adbc-888c8010c799_story.html

Tunis Agenda for the Information Society, 18 November 2005. Retrieved from http://www.itu.int/wsis/docs2/tunis/off/6rev1.html

US Department of Commerce (DoC) Press Release 'NTIA Announces Intent to Transition Key Internet Domain Name Functions', 14/03/2014. Retrieved from http://www.ntia.doc.gov/press-release/2014/ntia-announces-intent-transition-key-internet-do main-name-functions. 